\section{THE ACOUSTIC TRANSPARENCY AND OPACITY OF THE ATMOSPHERE*}

\section{II.}

WE have now to consider the complementary side of the phenomena. A stratum of air, 3 miles thick, on a perfectly calm day, has been proved competent to stifle both the cannon. ade and the horn-sounds employed at the South Foreland; while the observations just recorded, one and all, point to the mixture of air and aqueous vapour as the cause of this extra. ordinary phenomenon. Such a mixture could fill the atmosphere with an impervious acoustic cloud on a day of perfect optical transparency. But, granting this, it is incredible that so great a body of sound could utterly disappear in so short a distance, without rendering any account of itself. Supposing, then, instead of placing ourselves behind the acoustic cloud, we were to place ourselves in front of it, might we not, in accordance with the law of conservation, expect to receive by reflection the sound which had failed to reach us by transmission? The case

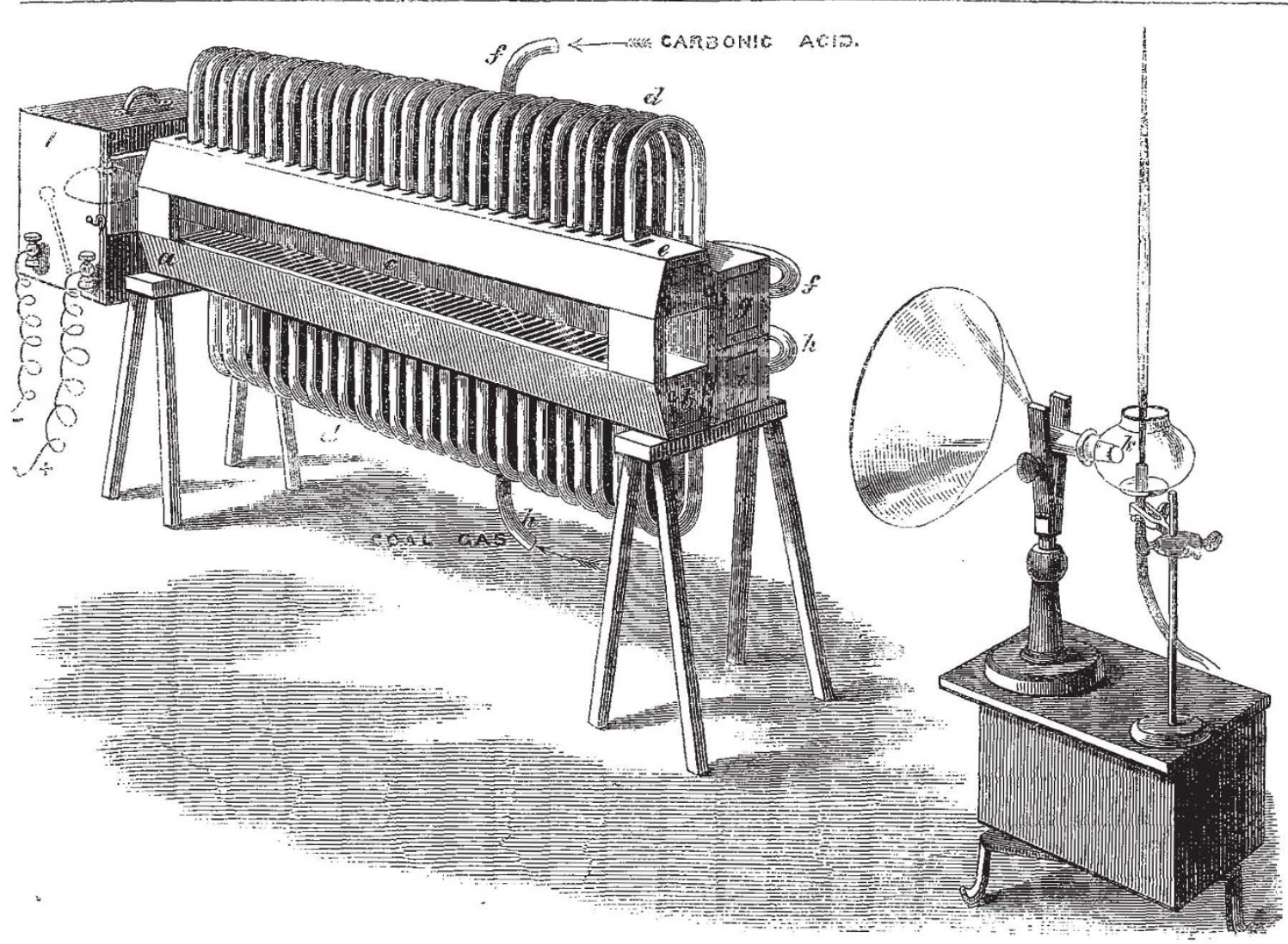

[A tunnel 2 in. square, $4 \mathrm{ft} .8 \mathrm{ln}$. long, open at both ends, and having a glass front, runs through the box $a b$. The space above and below is divided into cells opening into the tunnel by oblong orifices exactly corresponding vertically. Each alternate cell of the upper series-the Ist, 3 rd, 5 th, \&c.-communicates by a tube $(d d)$ with the upper reservoir $(g)$, its counterpart in the lower series having a free outlet into the air. In like manner the 2 nd, 4th, 6th, \&c., of the lower series of cells are connected with the lower reservoir $(i)$; and each has its direct passage into the air through the cell immediately above it. The gas distributors are filled from both ends at the same time ; the upper with carbonic acid gas, the lo ver with coal-gas, by branches from their respec. tive supply pipes $(f, h)$. A well-padded box $(l)$ opening upon the end of the tunnel forms a little cavern, whence the sound-waves are sent forth by an electric bell. A few feet from the other end of the tunnel, in a direct line, is a sensitive flams $(k)$, provided with a funnel as sound collector, and guarded from chance currents by a shade.

The bell was set ringing. The flame, with quick response to each blow of the hammer, emitted a sort of musical roar, so regular were its alternate shortenings and lengthenings as the successive sound-pulses reached it. The gases were then admitted. Twenty-five flat jets of coal gas ascended from the tubes below, and twenty-five cascades of carbonic acid poured down from the tubes above. That which was a homogeneous medium had now fifty limiting surfaces, from each of which a portion of the sound was thrown back. In a few moments these successive reflections became so effective that not a single sound-wave having sufficient power to affect a fiame so sensitive as to be knocked down, crushed, as it were, by a chirrup, or jingle, at twenty feet distance, could pierce the clear, optically-transparent, but acoustically-opaque atmosphere in the tunnel. So long as the gases continued to flow, the flame remained perfectly tranquil. When the supply was cut off, the gases rapidly diffused into the air. The atmosphere of the tunnel became again homogeneous, and therefore acoustically transparent, and the flıme bowed down to each sound-pulse as before. Alternate layers of common air and air saturated with various vapours produce the same effect.]

would then be strictly analogous to the reflection of light from an ordinary cloud to an observer placed between it and the sun.

My first care, in the early part of the day in question, was to assure myself that our inability to hear the sound did not arise from any derangement of the instruments. At one P.M. I was

* Royal Institution, Friday evening Discourse by Prof. Tyndall, D.C. L. L.L.D., F.R.S. Jan. r6. (Continued from page 253.) rowed to the shore, and landed at the base ot the South Foreland cliff. The body of air which had already shown such extraordinary power to intercept sound, and which manifested this power still more impressively later in the day, was now in front of us. On it the sonorous waves impinged, and from it they were sent back to us with astonishing intensity. The instruments, hidden from view, were, on the summit of a cliff 
235 feet above us, the sea was smooth and clear of ships, the atmosphere was withunt a cloud, and there was no object in sight which could possibly produce the observed effect. From the perfectly transparent air the echoes came, at first with a strength apparently but little less than that of the direct sound, and then dying gradually and continuously away. The remark of my companion, Mr. Edwards, was: "Beyond saying that the echoes seemed to come from the expanse of ocean, it did not appear possible to indicate any more definite point of reflection." Indeed, no such point was to be seen ; the echoes reached us as if by magic, from absolutely invisible walls. Arago's notion that clouds are necessary to produce atmospheric echoes is therefore untenable.

The reflection from aërial surfaces has never been experi. mentally demonstrated. It is wholly a matter of inference, and I wished very much to reduce it to demonstration. I made one or two rough experiments on the transmission of sound through a series of flames; and no doubt by proper arrangement such experiments might be made successful. I then thought that alternate layers of carbonic acid and coal gas, the one rising by its lightness, the other falling by its weight, would supply a heterogeneous medium suitable for the demonstration. To my assistant, Mr. Cottrell, who possesses in an eminent degree the skill of devising apparatus, I communicated this idea, leaving the realisation of it wholly to him, and he has carried it out in the most admirable manner. (For a sketch and description of the apparatus, see previous page).

During my recent visit to the United States $I$ accompanied General Woodruff, the engineer in charge of two of the lighthouse districts, to the establishments at Staten Island and Sandy Hook, with the express intention of observing the per. formance of the steam-syren, which, under the auspices of Prof. Henry, has been introduced into the lighthouse system of the United States. Such experiments as were possible to make under the circumstances were made, and I carried home with me a somewhat vivid remembrance of the mechanical effect of the sound of the steam syren upon my ears and body generally. This I considered to be greater than the similar efiect produced by the horns of IVIr. Holmes; hence the desire, on my part, to see the syren tried at the South Foreland. The formal expression of this desire was anticipated by the Elder Brethren, while their wishes were in turn anticipated by the courteous kindness of the Lighthouse Board at Washington. Informed by Majur Elliott that our experiments had begun, the Board forwarded to the Corporation, for trial, the noble instrument now mounted at the South Foreland. The principle of the syren is easily understood. A musical sound is produced when the tympanic membrane is struck periodically with sufficient rapidity. The production of these tympanic shocks by puffs of air was first realised by Dr. Robison. But the syren itself is the invention of Cagniard de la Tour. He employed a box with a perforated lid, and above the lid a similarly perforated disc, capable of rotation. The perforations were oblique, so that when wind was driven through the disc was set in motion. When the perforations coincided a puff escaped, when they did not coincide the current of air was cut off. The regular succession of impuises thus imparted to the air produce a musical note. Even in is small form, the instrument is capable of producing sounds of great intensity. The syren has been impreved upon by Dove, and notably developed by Helmholtz.

In the steam syren patented by Mr. Brown of New York, a fixed disc and a rotatory disc are also employed, radial slits being cut in both discs instead of circular apertures. One disc is fixed across the throat of a trumpet-shaped tube, $16 \frac{1}{2} \mathrm{ft}$. long, 5in. diameter where the disc crosses it, and gradually opening out till at the other extremity it reaches a diameter of $2 \mathrm{ft} .3$ in. Behind the fixed disc is the rotating one, which is driven by separate mechanism. The trumpet is mounted on a boiler. In our experiments steam of yolbs. pressure has for the most part been employed. Just as in the air-syren, when the radial slits of the two discs coincide, a puff of steam escapes. Sound-ivaves of great intensity are thus sent through the air; the pitch of the note produced depending on the rapidity with which the puffs succeed each other; in other words, upon the velocity of rotation.

On October 8 I remained some time at the Foreland, listening to the echoes. Of the horn-echoes I have already spoken : those of the syren were still more extraordinary. Like the others they were perfectly continuous, and faded as if into the distance gra. dually away. The single sound seemed rendered complex and multirudinuus by its echoes, which resembled a baxid of trumpeters first responting close at band, and then retreating rapidly from us towards the coast of France. The syren echoes had eleven seconds duration, those of the horn eight seconds. With sounds of the same pitch the duration of the echo might be taken as a measure of the penetrative power of the sound.

I moved away from the station so as to lower the power of the direct sound. This was done by dropping into the soundshadow behind an adjacent eminence. The echoes heard thus were still more wonderful than before. In the case of the syren, moreover, the reinforcement of the direct sound by the echo was distinct. One second after the commencement of the syren blast, the echo struck in as a new sound. This first echo, therefore, must have been flung back by a body of air not more than 600 or $700 \mathrm{ft}$. in thickness.

There appears to be a direct connection between the duration of the echoes and the clistance penetrated by the sound. On October I7 the perfect clearness of the afternoon caused me to choose it for the examination of the echoes. The echoes of that day, when our transmitted sound reached its maximum, exceeded in duration those of all other days. We heard the syren fifteen miles off. On the close of the day we found its echoes fourteen to fifteen seconds in duration, this long duration indicating the distance from which they were thrown back.

The visual clearness of the atmosphere on the morning of Oct. 8 , was very great, the coast of France was very plainly seen, the Grisnez lighthouse, and the monument and cathedral of Boulogne, were discinctly visible to the naked eye. At $5 \frac{1}{4}$ miles from the station, the horn was heard feebly, the syren clearly. At 2.3O P.M., a densely black scowl overspread the heavens to the W.S.W. At this hour, the distance being 6 miles, the horn was heard very feebly, the syren more distinctly, all being hushed on board during the observations. A squall now approached us from the west. In the Alps, or elsewhere, I have rarely seen the heavens blacker. Vast cumuli floated in the N.E. and S.E.; vast streamers of rain were seen descending W.N.W. ; huge scrolls of clour to the $\mathrm{N}$

At 7 miles distance the syren was not sirong, and the horn was very feeble.

The hesy rain at lengtin reached us, but although it was fall. ing all the way between us and the Foreland, the sound, instead of being deadened, rose perceptibly in power. Hail was now added to the rain, and the shower reached a tropical violence. We stopped. In the midst of this furious squall both the horn and the syren were distinctly heard, and as the shower lightened, thus lessening the local pattering, the sounds so rose in power that we heard them at a distance of $7 \frac{1}{2}$ miles distinctly louder than they had been heard through the rainless atmosphere at 5 miles. This observation is entirely opposed to the statement of Derham, which has been repeated by all writers since his time, regarding the stifling influence of falling rain upon sound. But it harmonises perfectly with our experience of July 3 , which proved water in a state of vapour so mixed with air as to form non homugeneous parcels, to be a most potent influence as regards the stoppage of sound. Prior to the violent shower, the air had been in this flocculent condition, but the descent of the rain and bail restored in part the homogeneity of the atmosphere, and angmented its transmissive power. There may be states of the atmosphere assuciated with rain unfavourable to sound, but to rain itself I have never been able to trace the slightest deadening effect.

The observations continued till November 25 . Up to that date we harl no fog, but the experience of July $\mathbf{I}$ and of October 30, entirely destroy the notion that optical transparency and acoustic transparency go hand-in-hand. Both were days of haze sufficiently thick to hide the cliffs of the Foreland, but on the former the sounds reached $\mathrm{I} 2_{4}^{3}$, and on the latter I I $\frac{1}{2}$ miles.

Reflection from the particles of fog and haze has been hitherto held to blot ont sound. The late dense fog in London enabled experiments to be made which entirely controvert this conclusion. On December Io I made some experiments over the Serpentine. The fog was very dense. Mr. Cotterell stood on the walk below the south-west end of the bridge dividing Hyde Park from Kensington Gardens, while I went to the eastern end of the Serpentine. Ho blew a dog-whistle, and an orgañ-pipe sounding $\mathrm{Mi}_{2}$, which corresponds to 380 waves a second. I heard both distinctly. I then changed places with him, and listening attentively at the lidge, heard for a time the distinct blast of the whistle only. The organ-pipe at length sent its deeper note to me across the 
water. It sometimes rose to great distinctness, and sometimes fell to inaudibility. These fuctuations, of which varions striking examples have been observed, are due to the drifting of acoustic clouds, which act upon a source of sound, as the drifting of ordinary clouds upon the sun. The whistle showed the same intermittence as to period, but in the opposite sense, for when the whistle was faint the pipe was strong, and vice versî.

There seemed to be an extraordinary amount of sound in the air. It was filled with a resonant roar from the Bayswater and Knightsbridge roads. The railway whistles were extremely dis. tinct, while the fog-signals exploded at the various metropolitan stations kept up a loud and almost constant cannonade. I could by no means reconcile this state of things with the statements so categorically made regarding the influence of fog.

The water was on this day warmer than the air, and the ascending vapour was instantly in part condensed, thus revealing its distribution. Instead of being uniformly diffused, it formed wreaths and striæ. I am pretty confident that had the vapour been able to maintain itself as such, the air would have been far more opaque to sound. In other words, I believe that the very cause which diminished the optical transparency of the atmosphere augmented its acoustical transparency.

This conclusion was confirmed by numerous observations made while the fog lasted."

On Dec. I 3 the fog was displaced by a thin haze. We could plainly see from one bank of the Serpentine to the other, and far into Hyde Park beyond. There was a wonderful subsidence of the sound of the carriages, church bells, \&c. Being at the bridge I listened for the sounds excited at the end of the Serpentine. With the utmost stretch of attention $I$ could hear nothing. I walked along the edge of the water towards Mr. Cottrell, and when I had lessened the distance by one half, the sound of his whistle was not so distinct as it had been at the bridge on the day of the densest fog. Hence the optical cleansing of the air by the melting of the fog had so darkened it acoustically, that a sound generated at the end of the Serpentine was lowered to at least one-fourth of its intensity at a point midway between the end and the bridge.

This opportune fog enabled me to remove the last of a congeries of errors which, ever since the year 1708 , have attached themselves to this question. As regards phonic coast-signals, we now know exactly where we stand.

It is worth observing he; e that the solution of the deportment of hail, rain, snow, haze, and iog, as regards sound, derends entirely upon observations made on the 3 rd of July, which was about the last day that one would have chosen for experiments on for-signals. Indeed, it had been distinctly laid down that observations on such a day would be useless; that they might indeed enab?e us to weed away bad instruments from good ones, but could throw no light whatever on the question of fogsignaling. That the contrary is the case, is an illustration of the fact that the solution of a question often lies in a direction diametrically opposed to that in which it appears to lie. +

\section{EXTRACTS FROM AN ADDRESS BY SIR W. THOMSON, TO THE SOCIETY OF TELE- GRAPHIC ENGINEERS}

I HAVE advisedly, not thoughtlessly, used the expression "terrestrial electricity." It is not an expression we are accustomed to. We are accustomed to "terrestrial magnetism ;" we are accustomed to atmospheric electricity. The electric telegraph forces us to combine our ideas with reference to terrestrial magnetism and atmospheric electricity. We must look upon the earth and the air as a whole-a globe of earth and air-and consider its electricity whether in rest or in motion. Then, as to terrestrial magnetism, of what its relation may be to perceptible electric manifestations we at present know nothing.

Yon all know that the earth acts as a great magnet. Dr. Gilberi, of Colchester, made that clear nearly 300 years ago; but how the earth acts as a great magnet-how it is a magnet,- wheiher an electro-magnet in virtue of currents revolving round under the upper surface, or whether it is a magnet like a mass of steel or load-stone, we do not know. This we do know, that

* Since the first notices of this iectere appeared in the newspapers, strong confirmatory evidence has been received.

t The foregoing report was compiled from the notes of Prof. Tyndall. I is published with Prof. Tyndall's sanction, but was not written by himself. it is a variable magnet, and that a first approximation to the variation consists in a statement of motion round the axis of figure-motion of the magnetic poles, round the axis of figure, in a period of from 900 to 1,000 years. The earth is not a uniformly magnetised magnet with two poles, and with circles of symmetry round those poles. But a first expression-as we should say in mathematical language the first " harmonic term" --in the full expression of terrestrial magnetism is an expression of a regular and symmetrical distribution such as $I$ have indicated. Now, this is quite certain, that the axis of this first term, so to speak, or this first approximation, which, in fact, we might call the magnetic axis of the earth, does revolve round the axis of figure.

When the phenomena of terrestrial magnetism were first somewhat accurately observed about three hundred years ago, the needle pointed here in England a little to the east of north; a few years later it pointed due north; then, until about the year 1820 , it went to the west of north; and now it has come back towards the north. The dip has experienced corresponding variations. The dip was first discovered by the instrument maker, Robert Norman, an illustration, I may mention in passing, of the benefits which abstract science derives from practical applications-one of the rost important fundamental discoveries of magnetism brought back to theory by an instrument maker who made mariner's compasses. Robert Norman, in balancing his compass cards, noticed that after they were magnetised one end dipped, and he examined the phemonenon and supported a needle about the centre of gravity, magnetised it, and discovered the dip. When the dip was first so discovered by Robert Norman it was less than it is now. The dip has gone on increasing, and is still increasing; but about 50 years ago the deviation from true north was greatest. Everything goes on as if the earth had a magnetic pole revolving from west to east round the true North Pole, at a distance of $20^{\circ}$ from it. About three hundred years ago its azimuth from England was a little to the east of the north pole: then it came round, moving eastwards on the far side of the north pole, and round in a circle towards us on the left-hand side of the north pole, as looked to from England. That motion in a circle round the north pole has already been experienced within the period during which somewhat accurate measurements have been made-has been experienced to the extent of rather more than a quarter of the whole revolution and we may expect that about 200 years from the present time the magnetic pole will be between England and the North Pole; so that the needle will thus point due north, and the dip be greater than it has been for $\mathrm{I}, 000$ years, or wiil be for another. It is one of the greatest mysteries of science, a mystery which might almost say is to myself a subject of daily contemplationwhat can be the cause of this magnetism in the interior of the earth? Rigid magnetisation, like that of steel or the loadstone, has no quality in itself in virtue of which we can conceive it to migrate round in the magnetised bar. Electric currents afford the more favoured hypothesis; they are more mobile. If we can conceive electric currents at all, we may conceive them flitting about. But what sustains the electric currents? People sometimes say, heedlessly or ignorantly, that thermo electricity does it. We have none of the elements of the problem of thermo-electricity in the state of underground temperature which could possibly explain, in accordance with any knowledge we have of thermo-electricity, how there conld so be sustained currents round the earth. And if there were currents round the earth, regulated by some cause so as to give them a clefinite direction at one time, we are as far as ever from explaining how the channel of those currents could experience that great secular variation which we know it does. Thus we have merely a mystery. It would be rash to suggest even an explanation. I may say that one explanation has been suggested. It was suggested by the great astronomer, Halley, that there is a nucleus in the interior of the earth, and that the mystery is explained simply by a magnet not rigidly connected with the upper crust of the earth, but revolving round an axis differing from the axis of rolation of the outer crust, and exhibiting a gradual precessional motion independent of the precessional motion of the outer rigid crust. I merely say that has been suggested. I do not ask you to judge of the probability : I would not ask myself to judge of the probability of it. No other explanation has been suggested.

But now, I say, we look with hopefulness to the practical telegraphist for data towards a solution of this grand problem. The terrestrial magnet is subject, as a whole, to the grand secular variation which $I$ have indicated. But, besides that, there are 